\title{
Uma análise da consistência do ICMS ecológico do Ceará enquanto mecanismo de incentivos e redistribuição de recursos financeiros
}

\section{A consistency analysis of Ceara's ecologic ICMS as an incentive and financial redistribution mechanism}

\author{
Cláudio André Gondim Nogueira ${ }^{1}$ \\ Mário Augusto Parente Monteiro² \\ Adriana Carla Avelino Mazza ${ }^{3}$
}

\section{Resumo}

Em 2009, o Governo do Estado do Ceará implementou uma nova metodologia de cálculo do rateio da cota parte do ICMS entre os municípios, envolvendo três índices: educação, saúde e meio ambiente. Trata-se de um mecanismo cujo objetivo é dar incentivos para uma maior competição entre as gestões municipais e gerar uma distribuição mais equitativa dos recursos. Nesse contexto, com o cálculo do Índice de Qualidade do Meio Ambiente (IQM), implementou-se a ideia do ICMS Ecológico no Ceará. Então, o principal objetivo deste estudo é analisar a consistência do ICMS Ecológico como um mecanismo de incentivos para a melhoria das condições ambientais. Foram utilizadas duas abordagens: uma análise do marco lógico do mecanismo de incentivo com base nos objetivos da nova metodologia da cota parte e a outra a partir de uma regressão múltipla do tipo Tobit. A partir da análise mais geral, concluiu-se que o ICMS Ecológico, teoricamente, pode induzir a uma maior competição e à melhora das condições ambientais dos municípios, especialmente a longo prazo, embora haja questões importantes a considerar, principalmente no que

Mestre em Economia pela Universidade Federal do Ceará (1999) e pela Pennsylvania State University (2002). Doutorando em Administração pelo PPGA/UNIFOR. Professor e pesquisador da UNIFOR. Endereço: Universidade de Fortaleza, Programa de Pós-Graduação em Administração de Empresas (PPGA/UNIFOR). Av. Washington Soares, 1321, Edson Queiroz, 60811-905, Fortaleza/CE, Brasil. E-mail: claudioandre@unifor.br

2 Mestre em Administração de Empresas pela Universidade de Fortaleza (2001). Doutorando em Administração e Professor Adjunto da UNIFOR. Analista de Regulação da Agência Reguladora do Estado do Ceará (ARCE). Endereço: Universidade de Fortaleza, Programa de Pós-Graduação em Administração de Empresas (PPGA/UNIFOR). Av. Washington Soares, 1321, Edson Queiroz, 60811-905, Fortaleza/CE, Brasil. E-mail: mariomonteiro@unifor.br

3 Mestre em Administração pela Universidade Estadual do Ceará - UECE (2007). Professora da Faculdade Integrada do Ceará-FIC. Doutoranda em Administração de Empresas da UNIFOR. Endereço: Universidade de Fortaleza, Programa de Pós-Graduação em Administração de Empresas (PPGA/UNIFOR). Av. Washington Soares, 1321, Edson Queiroz, 60811-905, Fortaleza/CE, Brasil. E-mail: adriana.a.mazza@gmail.com 
se refere à compatibilização entre o benefício concedido e o estímulo à participação por parte dos municípios. Já a partir da análise de regressão, verificou-se uma tendência de privilegiar aqueles municípios que já estavam, de maneira geral, com melhores condições, o que demonstra certa inconsistência do mecanismo em questão em relação ao mecanismo mais geral do qual ele faz parte.

Palavras-chave: ICMS Ecológico. Gestão por Resultados. Análise de Consistência.

\section{Abstract}

Since 2009, the Ceara State Government has implemented a new methodology to distribute the resources from the main state tax (ICMS) among its municipalities, which involves three indices (education, health, and environment). This is a mechanism that aims to induce a greater competition and to generate a more equitable distribution of financial resources amongst the state's municipalities. In this context, with the Environmental Quality Index (IQM), the idea of a green tax was finally implemented. Hence, the main objective of this paper is to analyze the consistency of such a tax as an incentive mechanism for the improvement of environmental conditions. Two approaches were used: an analysis of the logical framework of the incentive mechanism based on the goals of the new methodology and another based on the results from a TOBIT multiple regression analysis. From a more general analysis it was possible to conclude that, in theory, the environmental tax is able to induce a greater competition and improvements in environmental conditions, especially in the long run, even though there are important concerns to consider, especially in regard to the relation between the benefit conceded and the municipality's willingness to participate. The regression analysis, however, indicated that the mechanism tends to reward mainly the municipalities that, in general, already presented better conditions, which could be considered as an inconsistency of the mechanism in respect to the general mechanism that it is a part of.

Keywords: Ecological ICMS. Result-Based Management. Consistency Analysis.

\section{Introdução}

A preservação do meio ambiente apresenta-se como condição necessária à continuação da vida na Terra. Nesse sentido, a degradação ambiental tornou-se uma preocupação imediata para todos os países do mundo, sejam eles industrializados ou não, na medida em que ameaça os fundamentos de sustentação da vida no planeta. A consciência dos limites do estoque de recursos naturais disponíveis à humanidade, aliada 
à noção de que todo ser humano tem direito a um habitat que forneça a melhor qualidade de vida possível, tem dado início a um processo de busca de alternativas e instrumentos voltados para a preservação e a reparação do meio ambiente.

Neste contexto, destaca-se o Imposto de Circulação de Mercadorias e Serviços (ICMS) Ecológico como uma alternativa para operacionalização do princípio da precaução, ou seja, para criar condições objetivas que favoreçam as iniciativas que busquem minimizar/eliminar os problemas ambientais. O ICMS Ecológico possui esta função, pois se embasa num incentivo dado aos municípios que buscam alternativas de gestão ambiental. Ele não é um novo tributo ou um aumento de alíquota do tributo já existente, mas uma alternativa para aumentar o repasse da cota-parte do ICMS a partir da preservação ambiental.

Ao longo dos últimos anos, muitos estados brasileiros adotaram tal política, pois além de o ICMS ser o imposto de maior importância em nível estadual, representando em média $90 \%$ da receita tributária dos Estados, demonstra, através do ICMS Ecológico, uma promissora alternativa de política de incentivo à preservação ambiental.

Assim, o presente artigo tem por objetivo, a partir de uma revisão dos fundamentos conceituais associados à utilização de instrumentos econômicos como parte de políticas públicas de gestão ambiental, realizar uma análise de aspectos referentes à efetividade de seu emprego no Estado do Ceará, notadamente, em termos dos critérios de distribuição dos recursos financeiros mobilizados pelo ICMS Ecológico. Os resultados obtidos evidenciam elementos relevantes para o aperfeiçoamento desse mecanismo de política pública voltado ao meio ambiente.

\section{Bases conceituais e justificativa econômica do ICMS Ecológico}

O ponto de partida para o presente trabalho é a percepção de que a elaboração e a implementação de políticas públicas voltadas para a sustentabilidade ambiental implica utilização e adoção de múltiplos 
mecanismos de ação estatal. Nesse sentido, torna-se necessária uma discussão em torno das características dos mecanismos atualmente empregados, bem como daqueles que apresentam um potencial de utilização.

De modo geral, em relação à utilização de instrumentos de políticas públicas com o objetivo de orientar as decisões dos agentes econômicos com impactos sobre o meio ambiente, observa-se a predominância do emprego de mecanismos regulatórios nas políticas ambientais, baseados no "princípio do poluidor-pagador", os quais buscam internalizar os custos sociais das externalidades ambientais nas atividades privadas (PIGOU, 1932), ainda que, mais recentemente, seja crescente a percepção da importância que os instrumentos econômicos podem desempenhar nestas políticas (BARBIERI, 2011; GOULDER, 2000; HAHN, 2000; PORTNEY, 2008; TIETENBERG, 2000).

Seguindo uma abordagem alinhada com a obra de Pigou (1932), observa-se que na política ambiental do Brasil há uma propensão à utilização de instrumentos econômicos como uma abordagem complementar. A necessidade de incentivar os municípios a desenvolverem ações de proteção ao meio ambiente, proporcionando melhorias na qualidade de vida de suas populações atuais e futuras, além da escassez de recursos financeiros para o gerenciamento destas ações, mostra a necessidade de o Estado criar um mecanismo financeiro que, efetivamente, estimule as ações ambientais (HEMPEL, 2008).

Em situações nas quais prevalece a escassez de recursos financeiros, a disposição a receber é mais alta que a disposição a pagar (HEMPEL, 2008). A cobrança de impostos ao poluidor (princípio poluidorpagador) é um modo de internalizar os custos sociais no sistema de preço do poluidor, desse modo, afetando a demanda pelos seus produtos e a realização de seus lucros (BARBIERI, 2011).

Já o princípio do protetor-recebedor defende que o agente público ou privado o qual, de alguma forma, protege um bem natural que reverte em benefício da comunidade, deve receber uma compensação financeira como incentivo pelo serviço prestado. Esse princípio serve de 
incentivo econômico a quem protege áreas e representa um símbolo de justiça econômica no momento em que valoriza os serviços ambientais prestados, remunerando este serviço; parte do pressuposto que se tem valor econômico é justo que se receba por ele (HEMPEL, 2008).

No atual contexto em que as informações são mais bem difundidas e que os cidadãos têm mais consciência de seus direitos, o Governo é levado a desenvolver políticas públicas que efetivamente melhorem a qualidade de vida da população. A maioria dos estados brasileiros possui uma péssima distribuição de renda e uma oferta insuficiente de recursos públicos na área da saúde, educação e meio ambiente (HOLANDA, et al. 2007). Para lidar com essa situação, é primordial que se busque uma alocação eficiente dos recursos públicos. Tal eficiência pode ser alcançada através de mecanismos de incentivo desenhados para priorizar a melhoria de indicadores socioambientais e, consequentemente, uma alocação mais equitativa dos recursos públicos.

Nesse contexto, a política ambiental apoia-se, para atingir seus objetivos propostos, em dois conjuntos distintos de instrumentos, a saber: os chamados instrumentos de comando e controle, tradicionalmente os mais usados, e os instrumentos econômicos, os quais estão assumindo papel de grande relevância no gerenciamento dos recursos naturais (ALMEIDA, 1998; BARBIERI, 2011; ELZEN, B.; WIECZOREK, 2005; PORTNEY, 2008).

Os instrumentos de comando e controle são caracterizados pela regulação direta, tendo como objetivo induzir a mudança de comportamento dos agentes poluidores por meio de (i) padrões de poluição para fontes específicas, (ii) controle de equipamentos, (iii) controle de processos, (iv) controle de produtos, (v) proibição total ou restrição de atividades em determinadas áreas ou períodos do dia, (vi) concessão de licenças não comercializáveis, (vii) fixação de padrões de qualidade ambiental e zoneamento, (viii) e controle do uso dos recursos naturais por intermédio de fixação de cotas não comercializáveis de extração (ALMEIDA, 1998; PORTNEY, 2008). 
A principal característica destes instrumentos é tratar o poluidor como alguém que potencialmente pode cometer delitos, obrigando-o a se sujeitar às regras impostas, as quais, quando não cumpridas, possibilitam sua penalização ao final de processos administrativos ou judiciais específicos. Resta evidente, portanto, que a base para este controle é a existência de alguma forma de legislação (ALMEIDA, 1998; PORTNEY, 2008).

Os instrumentos econômicos, por sua vez, podem ser caracterizados como aqueles que induzem mudanças no comportamento dos agentes em relação ao meio ambiente, através da modificação dos preços relativos. O objetivo de tais instrumentos é a internalização dos custos ambientais na produção de bens e serviços por meio da utilização de taxas e subsídios, influenciando, dessa forma, o comportamento do agente econômico, no sentido de produzir uma atuação ambientalmente mais responsável. O uso seletivo de taxas e subsídios resulta na alteração dos preços relativos na direção desejada pelos formuladores da política ambiental (PERMAN, 1996). A internalização do custo ambiental busca eliminar a distância causada pelas externalidades, custos não captados no preço de mercado, entre o preço ótimo privado e o preço ótimo social (PORTNEY, 2008).

As definições para os instrumentos econômicos nem sempre são claras, envolvendo, no entanto, alguns elementos em comum: (i) a existência de um estímulo financeiro, (ii) a possibilidade de uma ação voluntária, (iii) o envolvimento de autoridades governamentais e (iii) a intenção de (diretamente ou indiretamente) manter ou melhorar a qualidade ambiental por meio da aplicação deste instrumento (OECD, 1992; ELZEN, B.; WIECZOREK, 2005; PORTNEY, 2008).

Os instrumentos econômicos têm uma série de características desejáveis: (i) a possibilidade de atingir qualquer meta desejada ao menor custo entre as possibilidades existentes (princípio da minimização de custos ou custo-efetividade), (ii) a possibilidade de gerar um incentivo permanente para a mudança de comportamento de empresas e indivíduos, e (iii) a dispensa de uma estrutura informacional cara e complexa, contrapondo-se à necessidade apresentada pelos 
instrumentos de comando e controle, no sentido da obtenção de informação acerca dos diferentes custos dos poluidores e consumidores (PORTNEY, 2008).

Cabe ressaltar que a adoção de instrumentos econômicos não deve ter a natureza exclusiva de outros mecanismos. Na realidade, é recomendável que possam ser aplicados em conjunto com políticas de comando e controle, assumindo, portanto, uma natureza complementar aos instrumentos regulatórios.

Nesse contexto, o ICMS Ecológico constitui uma alternativa de instrumento econômico aplicável à política ambiental no Brasil. Sendo, em essência, um dos critérios adotados pelos governos estaduais para o repasse dos $25 \%$ que os municípios têm direito sobre a arrecadação do Imposto sobre a Circulação de Mercadorias e Serviços, tal mecanismo tributário induz os governos locais a investirem em ações priorizadas pelo Estado, desta forma, produzindo resultados mais interessantes do que se estas mesmas ações fossem penalizadas pelo seu não cumprimento. Trata-se, portanto, de um instrumento com características de incentivo positivo e não-coercitivo. Outro ponto a ser destacado é a promoção da competição entre os municípios e a valorização daqueles que alcançaram bons resultados (HOLANDA et al., 2007).

Adicionalmente, cabe ressaltar que um ponto chave do incentivo dado através do ICMS Ecológico é a questão da compensação para aquele que protege, invertendo, assim, o que acontece quando a proteção é baseada em penalidades e que, por vezes, leva à aceleração da destruição do bem natural que se queria proteger.

\section{0 novo critério de rateio da cota parte do ICMS e o ICMS Ecológico no Ceará}

Recentemente, o Governo do Estado do Ceará propôs uma mudança na metodologia de cálculo do rateio da cota parte do ICMS entre os municípios do Ceará, instituída através da Lei № 14.023, de 17 de dezembro de 2007, e regulamentada pelos decretos $N^{\circ} 29.306$, de 05 
de junho de 2008, e № 29.586, de 19 de dezembro de 2008 (HOLANDA et al., 2007).

Anteriormente, a Lei $\mathrm{N}^{0}$. 12.612/96 dispunha sobre os critérios para distribuição da parcela de $25 \%$ da receita sobre as operações relativas à circulação de mercadorias e sobre prestações de serviços de transporte interestadual e intermunicipal e de comunicação (ICMS) que é distribuída entre os municípios cearenses. De acordo com essa lei, a distribuição da receita do ICMS entre os municípios deve ser feita seguindo os seguintes critérios:

I - 75\% referente ao Valor Adicionado Fiscal (VAF), obtido mediante a aplicação dos índices resultantes da relação percentual entre as médias dos valores adicionados ocorridos em cada município e dos valores adicionados totais do Estado, nos dois anos civis imediatamente anteriores;

II - 5\% conforme relação existente entre a população do município e a população total do Estado, medida segundo dados fornecidos pela Fundação Instituto Brasileiro de Geografia e Estatística (IBGE);

III - 12,5\% mediante a relação entre o somatório das despesas realizadas pelo município na manutenção e desenvolvimento do ensino nos termos do Art. 212, da Constituição Federal e do Art. $2^{\circ}$, da Lei ${ }^{\circ}$ $7.348 / 85$ e a receita municipal proveniente de impostos e transferências constitucionais federais e estaduais, calculada com base em dados relativos ao segundo ano civil imediatamente anterior, fornecidos pelo Tribunal de Contas dos Municípios.

IV - 7,5\% correspondente à quota a ser distribuída igualitariamente entre todos os municípios.

Como é possível perceber, a divisão dos recursos é muito influenciada pelo tamanho da população de cada município e, principalmente, por sua condição econômica. Mais especificamente, nesse sistema, os municípios maiores e com melhores condições econômicas seriam aqueles que tendem a receber uma parcela mais significativa dos recursos. 
Assim, a proposta de modificação consistiu basicamente em ratear os recursos da cota parte de forma mais equitativa e com maior efetividade, a partir da melhoria de indicadores sociais. Tratase de um mecanismo cujo objetivo primordial é dar incentivos para uma saudável competição entre as gestões municipais, de forma a recompensar aquelas que obtiverem as melhorias mais expressivas em indicadores selecionados de educação, saúde e meio ambiente, que são consideradas áreas estratégicas para o Governo do Estado (HOLANDA et al., 2007).

A referida proposta insere-se, também, na perspectiva da Gestão Pública por Resultados (GPR), que consiste na adoção por parte do setor público de uma postura empreendedora, voltada para o cidadão como cliente e para a satisfação de suas necessidades, buscando reduzir custos para a sociedade. Vale salientar que essa nova postura faz-se necessária no contexto atual, em que a sociedade passa a cobrar por mais eficiência, eficácia e efetividade na execução das políticas públicas e fiscaliza com mais intensidade as ações do Governo (HOLANDA, 2006; HOLANDA; ROSA, 2004; MEDEIROS et al., 2008).

Mais especificamente, já que a Constituição Federal prevê o critério relacionado ao Valor Adicionado Fiscal (VAF), a proposta de mudança na divisão dos recursos concentrou-se nos $25 \%$ restantes da cota parte. Mas no que consiste, de fato, a nova proposta? Como o rateio dos $25 \%$ da cota parte seria efetuado?

Conforme a proposta realizada (HOLANDA et al., 2007), os critérios a que se referem os parágrafos II, III e IV da Lei Estadual Nº. 12.612/96, relativos à cota parte dos municípios no ICMS, passaram, a partir de 2009, a ser os seguintes:

I. 18\% em função do Índice de Qualidade Educacional (IQE) de cada município, formado pelos indicadores de atendimento, aprovação e aprendizagem dos alunos, calculado com base em dados relativos aos dois anos civis imediatamente anteriores;

II. 5\% em função do Índice de Qualidade da Saúde (IQS) de cada município, calculado com base em dados relativos aos dois anos civis imediatamente anteriores; 
III. 2\% em função do Índice de Qualidade do Meio Ambiente (IQM) de cada município, calculado com base em dados relativos aos dois anos civis imediatamente anteriores.

Conforme (HOLANDA et al., 2007), o IQE é constituído por indicadores de fluxo e estoque da qualidade do ciclo inicial da Educação básica $-1^{\mathrm{a}}$ a $5^{\mathrm{a}}$ série do Ensino Fundamental (EF) - e indicadores de alfabetização da $2^{a}$ série do EF, divididos em dois sub-índices: o Índice de Qualidade do Ensino Fundamental (IQF), que representará 1/3 do IQE, e o Índice de Qualidade da Alfabetização (IQA), que representará os 2/3 restantes. O IQF é calculado a partir da taxa de aprovação nas séries iniciais do EF, com peso de $20 \%$ no índice, e o desempenho dos estudantes em exames padronizados (Prova Brasil ou Sistema Permanente de Avaliação da Educação Básica (SPAECE), com peso de $80 \%$. Já o Índice de Qualidade da Alfabetização é calculado a partir dos resultados do Exame da Alfabetização dos Estudantes da $2^{a}$ séries do Ensino Fundamental, o qual será realizado pela Secretaria de Educação do Estado do Ceará (SEDUC). Esse exame visa monitorar a alfabetização dos jovens nas séries iniciais, atribuindo nota para todos os Municípios Cearenses.

Já para o cálculo do Índice de Qualidade da Saúde, utilizou-se a Taxa de Mortalidade Infantil como indicador das condições e políticas na área da saúde de cada município. O IQS considera, também, tanto o nível como a performance da diferença da Taxa de Mortalidade Infantil, com peso igual para cada componente (50\%), visando estimular a competição entre os municípios, especialmente porque a obtenção de uma boa performance é mais difícil para os municípios que já possuem taxas de mortalidade infantil relativamente baixas (HOLANDA et al., 2007).

Finalmente, com o cálculo do IQM, procurou-se incluir a proposta do ICMS Ecológico no rateio da cota parte entre os municípios cearenses. De acordo com Costa e Paiva (2009), os critérios metodológicos para o cálculo deste índice foram estabelecidos pelos artigos 16 a 21 do Decreto $N^{\circ}$ 29.306, de 5 de junho de 2008. Mais especificamente, 
os Artigos 18 e 19 do referido decreto discorrem sobre os critérios a partir de 2009, indicando que cada município deve receber o valor 1 (um) para o IQM, caso cumpra simultaneamente três critérios até 30 de junho de 2009, quais sejam: I - a implantação da Estrutura Operacional definida pelo Plano de Gerenciamento Integrado dos Resíduos Sólidos Urbanos (PGIRSU); II - a implantação da coleta sistemática e seletiva; e III - a apresentação da Licença de Instalação para a disposição final dos resíduos sólidos urbanos, preferencialmente consorciada. Caso um dos critérios não fosse cumprido, o valor do índice para o município seria igual a zero. Ademais, a partir de 2010, foi levada também em consideração a existência de um Sistema de Gerenciamento Integrado de Resíduos Sólidos Urbanos.

Vale salientar ainda que as participações dos municípios nos $2 \%$ dos recursos da cota parte seriam dadas pela razão entre o valor dos seus respectivos IQMs e a soma de todos os IQMs municipais, de forma similar às participações definidas pelo IQE e pelo IQS (COSTA ; PAIVA, 2009; HOLANDA et al., 2007).

O problema com essa metodologia proposta para o IQM, conforme Costa e Paiva (2009), é que ela se mostrou muito restritiva para o atual contexto dos municípios cearenses, uma vez que esses autores indicaram que nenhum deles foi capaz de cumprir simultaneamente todos os critérios propostos em 2009, causando uma indeterminação na distribuição dos recursos associados ao índice.

Assim, de forma a contornar esse problema que não havia sido previsto quando da elaboração do Decreto $n^{\circ}$ 29.306, o Governo do Estado do Ceará publicou o Decreto n² 29.881, de 31 de Agosto de 2009, que modifica os artigos supracitados, estabelecendo cinco critérios e atribuindo pesos a cada um. A principal alteração ocorreu no Artigo $\mathrm{n}^{\circ}$ 18 que, em conformidade com Costa e Paiva (2009, p. 7), propõe o seguinte:

Art.18 - A partir do ano de 2009, serão considerados para efeito de existência do Sistema de Gerenciamento Integrado de Resíduos Sólidos Urbanos, além do previsto no caput do Art.17, os seguintes requisitos: 
I - a implantação da Estrutura Operacional definida pelo PGIRSU;

II - a implantação da coleta sistemática;

III - a implantação da coleta seletiva;

IV - a apresentação da Licença de Instalação válida para a disposição final dos resíduos sólidos urbanos, preferencialmente consorciada; e

V - a apresentação de Licença de Operação válida para a Disposição Final dos resíduos sólidos urbanos.

$\S 1^{\circ}$ Para cálculo da soma ponderada em 2009, os requisitos, se cumpridos até o dia 30 de junho de 2009, terão os seguintes pesos na soma total ponderada: requisito I peso de 0,3 (três décimos), requisito II peso de 0,3 (três décimos), requisito III peso de 0,1 (um décimo) e requisito IV ou requisito $\mathrm{V}$ peso de 0,3 (três décimos).

$\S 2^{\circ}$. Com referência ao inciso IV do Art.18, municípios que já possuírem adequada disposição final de resíduos sólidos urbanos deverão apresentar a Licença de Operação renovada até o dia 30 junho de 2009.

$\S 3^{\circ}$ Para cálculo da soma ponderada a partir de 2010 , os requisitos, se cumpridos até o dia 30 de junho de cada ano, terão os seguintes pesos na soma total ponderada: requisito I peso de 0,1 (um décimo), requisito II peso de 0,1 (um décimo), requisito III peso de 0,3 (três décimos), requisito IV peso de 0,2 (dois décimos) e requisito $V$ peso de 0,3 (três décimos).

$\S 4^{\circ}$ No ano de 2010 e nos anos seguintes a este, para efeito de cálculo da soma ponderada, cada requisito deverá ser cumprido até o dia 30 de junho de cada ano.

Portanto, dada a reformulação do IQM, seria importante avaliar a consistência desse mecanismo no sentido de verificar se o seu desenho realmente favorece uma maior competição entre os municípios cearenses por recursos, o que traria efeitos positivos em longo prazo, na medida em que eles satisfaçam os critérios estabelecidos pela metodologia do índice descrita acima. 


\section{Análise de consistência: aspectos metodológicos}

$\mathrm{Na}$ análise de consistência do mecanismo do ICMS Ecológico no Ceará, foram utilizados, basicamente, dois tipos de abordagens.

Primeiramente, o ICMS Ecológico foi analisado considerando a perspectiva da proposta da redefinição dos critérios de distribuição da cota parte do ICMS entre os municípios cearenses. Essa abordagem envolveu uma discussão sobre os critérios selecionados, sobre a forma de calcular o IQM (inclusive comparando a sua metodologia com a dos demais índices, IQE e IQS) e sobre os objetivos propostos pelo mecanismo. Em particular, no que se refere a este último ponto, procurou-se avaliar teoricamente até que ponto as mudanças e os efeitos pretendidos podem ser efetivamente alcançados com base no desenho e no nível de intervenção do mecanismo de incentivos implementado.

Essa é basicamente uma análise de consistência do marco lógico do mecanismo de incentivo implementado. No caso, o marco lógico é uma forma sistemática de apresentar planos, programas e projetos considerando as relações existentes entre: os recursos disponíveis; as atividades que se planeja desenvolver; os produtos que se quer obter; e os resultados (transformações mais imediatas, obtidas em um período não muito longo) e impactos (transformações de médio e longo prazo) que se esperam alcançar (HOLANDA; ROSA, 2004). Ademais, seguindo as orientações desses autores, é importante mencionar que o marco lógico é concebido do fim para o começo e depois deve ser lido no sentido indicado anteriormente, dos insumos aos impactos, para se verificar a sua consistência.

No caso em questão, com a análise de consistência do marco lógico, procura-se avaliar até que ponto as atividades e os produtos contemplados pelo mecanismo potencialmente afetam o comportamento dos municípios no sentido de atingir os resultados que se pretende alcançar, isto é, aumentar o volume de recursos disponíveis devido ao preenchimento dos requisitos previstos no Artigo $n^{\circ} 18$ do Decreto $n^{\circ}$ 29.881, de 31 de Agosto de 2009, e melhorar a qualidade de vida da população. 
As conclusões dessa análise crítica do mecanismo de incentivos associado ao IQM, que serão apresentadas adiante, levaram a uma investigação sobre que fatores estão associados ao comportamento do referido índice que, por sua vez, mostraram-se bastante importantes para complementar a análise de consistência do mecanismo, bem como para fundamentar as propostas de melhoria das condições socioambientais dos municípios cearenses.

Assim, nesse sentido, foi proposta uma estratégia empírica, com base em uma regressão múltipla. No caso, utilizou-se como variável dependente o percentual repassado para cada município dos recursos associados ao resultado do IQM para 2010 (RIQM), cujos valores estão disponíveis em Costa e Paiva (2009) e no sítio da Secretaria da Fazenda do Estado do Ceará (SEFAZ), na Internet (www.sefaz.ce.gov.br).

Um conjunto de variáveis e índices de diversas fontes foi testado a fim de selecionar aqueles regressores que apresentaram uma significância estatística desejável, que proporcionassem o melhor nível de ajustamento do modelo aos dados e, principalmente, às premissas teóricas do método de estimação utilizado.

No caso, vale ressaltar que, dada a variável dependente em consideração, a estimação do modelo pelo método dos mínimos quadrados ordinários não é aconselhada, pois produziriam estimadores tendenciosos e inconsistentes (GUJARATI, 2006; WOOLDRIDGE, 2002 e 2006).

Assim, como se trata de uma variável dependente limitada já que um município nunca poderá receber menos que zero e não mais que dois pontos percentuais dos recursos ligados aos IQM, foi utilizado um modelo de regressão censurada acima e abaixo simultaneamente, caso especial do modelo Tobit (GUJARATI, 2006; WOOLDRIDGE, 2002 e 2006). Vale ressaltar que o valor censurado abaixo foi zero e, já que é pouco provável um município apenas obter todos os recursos referentes aos IQM, dados os critérios atuais relacionados ao índice, então foi escolhido como limite superior o máximo valor encontrado, uma vez que a metodologia de cálculo do índice em questão favorece que vários municípios obtenham a mesma participação. 
No caso das variáveis explicativas, após uma análise das possibilidades de acordo com as informações existentes ao nível municipal, foram escolhidas as seguintes:

IDM = Índice de Desenvolvimento Municipal, calculado para o ano de 2008;

DIST = Distância em linha reta em relação a Fortaleza (a capital do Estado), medida em quilômetros;

SV = Número de certificações obtidas pelos municípios no Programa Selo Verde durante o período de 2004 a 2009;

VAF = Valor Adicionado Fiscal dos municípios no ano de 2008;

RMF = uma variável binária que assume o valor igual a 1 (um) se o município pertencer à Região Metropolitana de Fortaleza ou 0 (zero), caso contrário; e

LOG $(A R E A)$ = o logaritmo natural da área dos municípios (medida em $\mathrm{Km}^{2}$ ).

O IDM é um índice calculado pelo Instituto de Pesquisa e Estratégia Econômica do Ceará (IPECE), calculado a cada dois anos e cujo principal objetivo é mensurar os níveis de desenvolvimento alcançados pelos municípios do Ceará, visando auxiliar na formação de políticas e na tomada de decisões na esfera pública ou privada. $\mathrm{Na}$ elaboração desse índice, são considerados 30 indicadores, abrangendo quatro grupos: i) Fisiográficos, fundiários e agrícolas; ii) Demográficos e econômicos; iii) Infra-estrutura de apoio; e iv) Sociais. Os valores desse índice encontram-se entre 0 e 100, de forma que os 184 municípios do Ceará possam ser hierarquizados e comparados. No caso, quanto maior o IDM, mais desenvolvido tende a ser o município em relação aos demais (IPECE, 2010).

Já o Selo Município Verde é um programa de certificação ambiental instituído pela Lei Estadual $n^{\circ} 13.304 / 03$ e regulamentado pelos Decretos n² 27.073/03 e n² 27.073/04 que, anualmente, identifica os municípios que atendem certos critérios referentes à conservação e ao uso sustentável dos recursos naturais. Mais especificamente, 
a qualidade ambiental é avaliada com base em vários critérios, quais sejam: legislação ambiental, instrumentos de gestão, infraestrutura, saúde, biodiversidade e educação ambiental. A análise desses critérios obedece a três sistemas de avaliação: gestão ambiental, mobilização ambiental e desempenho ambiental. Esse programa é acompanhado por um comitê gestor, presidido pelo Conselho de Políticas e Gestão do Meio Ambiente (CONPAM) e é composto, também, pelo Superintendente da Superintendência Estadual do Meio Ambiente (SEMACE), que atua como Secretário Executivo do comitê, e por representantes de entidades públicas, universidades e da sociedade civil organizada. Os dados referentes às certificações obtidas pelos municípios no período de 2004 a 2009 foram obtidos no sítio do CONPAM (www.conpam.ce.gov.br).

Os dados referentes ao VAF são calculados pela Secretaria da Fazenda do Estado do Ceará (SEFAZ) e foram obtidos para o ano de 2008 no seu sítio na Internet (www.sefaz.ce.gov.br). As distâncias em relação à Fortaleza e as áreas dos municípios foram obtidas junto ao IPECE. Vale salientar que a área foi calcula em logaritmo para diminuir a sua dispersão e para evitar violações nas suposições de normalidade e homocedasticidade dos resíduos da regressão.

\section{Resultados e discussão}

Para que a consistência do mecanismo de incentivo proposto seja analisada conforme critérios ambientais, primeiramente, é importante considerar os principais objetivos esperados pelos fazedores de política quando fizeram a proposta de modificação do cálculo da cota parte do ICMS.

No caso, conforme expresso anteriormente, um dos principais objetivos seria estimular um aumento da competição dos municípios por recursos através da busca por uma melhoria em certos indicadores estratégicos para o Estado do Ceará nas áreas de educação, saúde e meio-ambiente. Há que se considerar, também, que se deseja tornar a distribuição dos recursos mais equitativa entre os municípios, dando possibilidade para que municípios relativamente pequenos 
e pouco expressivos do ponto de vista econômico possam aumentar razoavelmente o montante de recursos recebidos decorrentes da arrecadação do ICMS (HOLANDA et al., 2007).

Avaliar o primeiro objetivo empiricamente não é fácil, especialmente se for considerado que o mecanismo foi colocado em prática há pouco tempo. Por outro lado, é possível considerar que esse tipo de incentivo é compatível com outros mecanismos que são apontados pela literatura especializada, que consideram o ganho de recursos financeiros em decorrência da realização de um esforço e a obtenção de um produto ou performance esperada (CAMPBELL, 2006; KREPS, 2003; LAFFONT e MARTIMORT, 2002; SALANIÉ, 1998).

Já o segundo objetivo foi considerado por Nogueira (2010) que, ao analisar a distribuição dos $25 \%$ dos recursos da cota parte do ICMS, os quais sofreram uma modificação na metodologia, nos anos de 2009 e 2010 comparativamente ao ano de 2008 (o último ano em que vigorou a metodologia anterior), concluiu que

A análise dos dados referentes à participação dos municípios cearenses na cota parte do ICMS antes (2008) e depois da mudança de metodologia de cálculo (2009 e 2010), indicou que houve, de maneira geral, mudanças expressivas na distribuição dos recursos. Após a implementação da nova metodologia, as distribuições tenderam a se tornar menos assimétricas e menos dispersas, ou seja, mais equitativas. Os resultados indicaram, também, que os municípios menores agora podem ocupar posições de melhor destaque quanto aos recursos da cota parte de acordo com os seus resultados alcançados nos indicadores de educação, saúde e meio-ambiente contemplados pela nova metodologia. Em termos práticos, isso pode significar aumentos consideráveis nas receitas de municípios pequenos que, se bem aplicadas, podem ajudar a melhorar as condições econômicas e sociais de suas populações (NOGUEIRA, 2010, p. 6).

Uma consideração importante neste ponto seria, portanto, a respeito da satisfação desses objetivos pelo mecanismo do ICMS Ecológico adotado pelo Ceará. Assim, no sentido de aprofundar essa 
questão, apresenta-se na Figura 1, conforme foi proposto anteriormente, o marco lógico referente ao mecanismo de incentivo delineado.

Figura 1 - Marco lógico do mecanismo de incentivo do ICMS Ecológico.

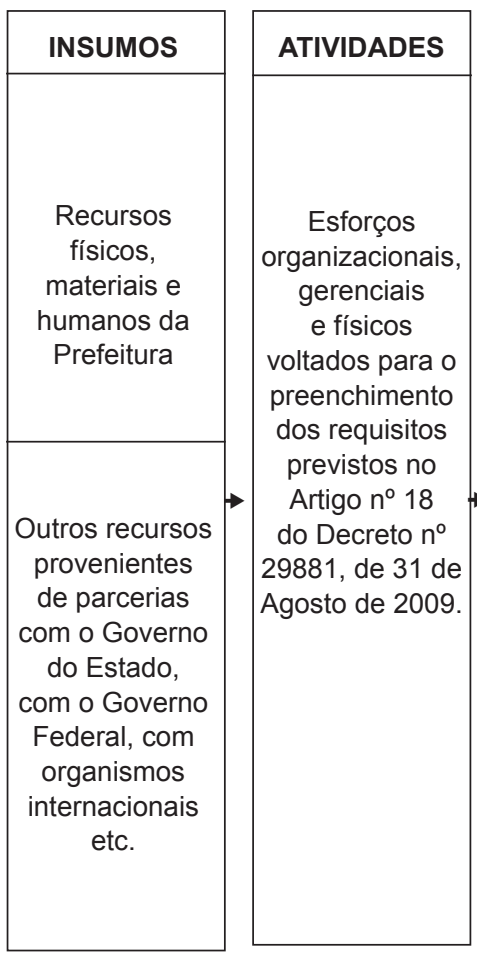

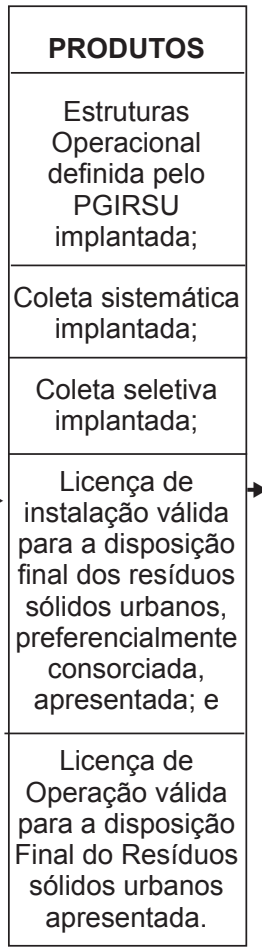

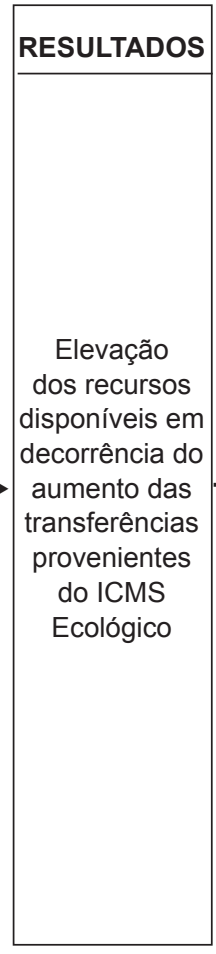

\begin{tabular}{|c|}
\hline IMPACTOS \\
\hline Aumento da \\
qualidade \\
de vida da \\
população \\
em \\
decorrência \\
da coleta \\
mais eficiente \\
dos resíduos \\
sólidos, \\
que gera \\
potenciais \\
melhorias nas \\
condições \\
de saúde \\
das pessoas \\
(menor \\
incidência de \\
doenças) e a \\
melhoria das \\
condições \\
ambientasi. \\
\hline
\end{tabular}

Fonte: Elaborado pelos autores.

No caso, visando aos resultados e impactos esperados que, nesse caso, são representados, respectivamente, pelos recursos adicionais provenientes do ICMS Ecológico e a melhoria da qualidade de vida da população (especialmente a menos favorecida), os municípios procurariam atender aos critérios estabelecidos no Artigo $n^{\circ} 18$ do Decreto $n^{\circ}$ 29.881. Para tanto, precisariam realizar esforços de várias naturezas (organizacionais, gerenciais, físicos etc.) e garantir recursos próprios ou provenientes de parcerias com o Governo do Estado ou outros organismos nacionais e internacionais que permitiriam que essas atividades fossem realizadas. 
Em seguida, analisando-se a sequência de etapas tal como foram apresentadas na Figura 1, dos insumos aos impactos, é possível constatar que a proposta de mecanismo é consistente com outros mecanismos propostos pela literatura, muito embora algumas questões ainda necessitem ser esclarecidas.

Assim, questões relacionadas ao caso em discussão estariam ligadas ao tempo necessário para induzir uma maior competição entre os municípios (se possível!), caso os recursos disponibilizados sejam suficientes para induzir esse aumento de competição e, enfim, se as administrações municipais serão ou não capazes de compensar a perda dos recursos provenientes do incentivo com relativa facilidade por outras fontes de receita, de forma a não obter satisfatoriamente o que se pretende com o mecanismo.

Em outras palavras, embora o mecanismo proposto tenha aparentemente uma estrutura lógica e consistente, faz-se necessário questionar se todos os municípios teriam, de fato, o interesse de obter os resultados esperados diante do custo e dos esforços a serem efetuados. Trata-se de uma análise de custo e benefício que é pertinente, pois os prefeitos podem em algum momento perceber, em particular, que os ganhos adicionais das transferências do ICMS Ecológico podem ser pequenos em relação aos recursos e esforços despendidos para a obtenção dos produtos.

Já a satisfação do segundo objetivo seria um pouco mais difícil para o ICMS Ecológico, especialmente no curto prazo, como será mais detalhado a seguir. No longo prazo, por outro lado, como foi argumentado acima, se todos os municípios tenderem a satisfazer os critérios propostos, no limite, todos eles, independentemente do tamanho e da importância econômica, tenderão a receber a mesma participação nos recursos relacionados ao IQM.

No curto prazo, devem-se considerar as diferenças no mecanismo do IQM com os demais mecanismos definidos a partir do IQE e do IQS. No caso, o IQM prevê a satisfação de certos critérios, como já foi argumentado antes, ao passo que o cálculo do IQE e do IQS contempla tanto o nível como a performance de indicadores de educação e saúde, 
respectivamente. Assim, para aqueles municípios já em melhores condições, o que seria refletido pelo nível dos indicadores poderia ser bem mais difícil conseguir boas performances nos indicadores, ao passo que, para aqueles em pior situação relativa, as chances de obtenção de melhores performances seriam maiores, favorecendo a uma maior participação nos recursos e a uma melhor distribuição dos recursos entre os municípios. Ademais, embora os indicadores considerados apresentem limites (e.g., a taxa de mortalidade infantil não pode ser menor que zero), os valores atuais apresentados pelos municípios ainda permitem avanços consideráveis (HOLANDA et al., 2007).

Desta forma, os resultados obtidos por Nogueira (2010) parecem ter sido bastante influenciados pelos comportamentos do IQE (principalmente) e do IQS, o que já seria esperado uma vez que eles representam, respectivamente, $18 \%$ e $5 \%$ dos repasses, ao passo que o IQM representa apenas 2\%. Mas, por outro lado, seria importante analisar que municípios tenderam a ser mais beneficiados inicialmente a partir dos critérios definidos na metodologia de cálculo do IQM, o que remete ao modelo de regressão múltipla mencionado anteriormente.

Na Tabela 1, são reportados os resultados da estimação do modelo de regressão proposto, efetuada com a ajuda do programa Econometric Views.

Tabela 1 - Resultados da Regressão Censurada (TOBIT)

\begin{tabular}{lllll}
\hline Variável & Coeficiente & Erro Padrão & Estatística z & P-valor \\
\hline C & 0,001545 & 0,005252 & 0,294265 & 0,7686 \\
IDM & 0,000179 & $7,53 \mathrm{E}-05$ & 2,376423 & 0,0175 \\
DIST & $-1,89 \mathrm{E}-05$ & $4,78 \mathrm{E}-06$ & $-3,957427$ & 0,0001 \\
SV & 0,001047 & 0,000358 & 2,921628 & 0,0035 \\
VAF & $5,70 \mathrm{E}-13$ & $1,91 \mathrm{E}-13$ & 2,985088 & 0,0028 \\
RMF & 0,010295 & 0,004405 & 2,337295 & 0,0194 \\
LOG(AREA) & 0,001095 & 0,000689 & 1,588027 & 0,1123 \\
\hline$R^{2}$ & 0,288295 & $R^{2}$ Ajustado & & 0,259827
\end{tabular}

Fonte: Elaboração própria com a ajuda do software Econometric Views. 


\section{Notas:}

[1] Variável Dependente: RIQM

[2] Método: ML - Censored Normal (TOBIT) (Quadratic hill climbing)

[3] Observações incluídas: 183 após ajustamentos

[4] Valor censurado à esquerda: 0

[5] Valor censurado à direita: 0,026720

[6] $\mathrm{N}^{\circ}$ de observações censuradas à esquerda: 10

[7] $\mathrm{N}^{\circ}$ de Observações censuradas à direita: 17

[8] $\mathrm{N}^{\circ}$ de Observações não censuradas: 156

[9] Foram utilizadas as covariâncias robustas de Huber/White para aumentar a eficiência dos estimadores.

De acordo com essa tabela, verificou-se uma relação positiva e estatisticamente significante a $5 \%$ do IDM, do número de certificações no Selo Verde (SV), do VAF e de pertencer à RMF com a variável dependente (RIQM). Ademais, obtiveram-se indícios de que a distância em relação à Fortaleza (DIST) influencia negativamente a participação nos recursos definidos a partir do IQM. Finalmente, o coeficiente de LOG(AREA), embora positivo, não se mostrou estatisticamente significante.

Vale salientar que, apesar do coeficiente de determinação ser reportado, deve-se lembrar que o método de estimação empregado é não linear e não busca a maximização deste coeficiente, como é o caso dos estimadores de mínimos quadrados (GUJARATI, 2006; WOOLDRIDGE, 2002 e 2006).

Logo, para validar os resultados da regressão, foram efetuados testes de hipóteses que são fundamentais para os modelos do tipo Tobit, referentes à normalidade e à homocedasticidade dos resíduos. No caso, a análise dos resíduos padronizados da regressão gerou uma estatística de Jarque-Bera igual a 1,6162, com p-valor igual a 0,4457. Como a hipótese nula desse teste normalidade é que a distribuição dos resíduos é normal, os resultados obtidos permitem concluir que essa hipótese não deve ser rejeitada.

No caso do teste da homocedasticidade, os resíduos padronizados da regressão foram ordenados e divididos em dois grupos de aproximadamente mesmo tamanho (92 observações no primeiro e 
91 observações no segundo), ou seja, o primeiro grupo representa os menores valores dos resíduos e, o segundo, os maiores valores. Em seguida, foram efetuados testes de igualdade de variância entre os dois grupos (BISQUERRA; SARRIERA; MARTINEZ, 2004). Os resultados são apresentados na Tabela 2.

Na análise da Tabela 2, é importante mencionar que após a separação em dois grupos (o dos menores e o dos maiores valores), os resíduos em cada grupo não apresentaram uma distribuição normal, o que já era esperado. Assim, deve-se considerar que os testes $\mathrm{F}$ e de Bartlett são mais sensíveis à não-satisfação dessa hipótese em relação aos demais testes considerados (Levene e Brown-Forsythe). Mas, de toda forma, todos os testes efetuados chegaram à mesma conclusão de que as variâncias dos dois grupos podem ser consideradas similares.

Tabela 2 - Testes de Igualdade de Variância dos Resíduos da Regressão Tobit

\begin{tabular}{lccc}
\hline Método & Graus de Liberdade & Valor & P-valor \\
\hline Teste F & $(91,90)$ & 1,052322 & 0,8092 \\
Bartlett & 1 & 0,058520 & 0,8089 \\
Levene & $(1,181)$ & 0,000442 & 0,9833 \\
Brown-Forsythe & $(1,181)$ & 0,000253 & 0,9873 \\
\hline
\end{tabular}

Fonte: Elaboração própria com a ajuda do software Econometric Views.

Então, com base nos resultados obtidos, o que se pode concluir a respeito do mecanismo de incentivos proposto a partir do IQM? A metodologia favorece ou não, no curto prazo, conforme o desenho da cota parte do ICMS previu, que a distribuição dos recursos entre os municípios cearenses seja mais igualitária?

De acordo com o sinal e a significância dos parâmetros estimados, verificou-se que, de maneira geral, os municípios que mais se beneficiaram com a metodologia do IQM foram aqueles com os maiores índices de Desenvolvimento Municipal; aqueles municípios que já vinham adotando melhores práticas ambientais em relação aos demais de acordo com a 
certificação do Selo Verde; que fazem parte da Região Metropolitana de Fortaleza (que concentra grande parte do PIB e da infraestrura do Estado) e/ou que estão localizados próximos a Fortaleza e que assim conseguem usufruir mais das externalidades positivas geradas pelo município mais rico e desenvolvido do Estado; e que têm uma maior arrecadação de ICMS (de acordo com o VAF).

Desta forma, verificou-se uma tendência de privilegiar através do ICMS Ecológico aqueles municípios que já estavam, de maneira geral, com melhores condições. Para ilustrar esse resultado, os dados mostram que, em 2010, o número máximo de critérios atendidos por um município específico foi igual a 3, e somente 17 dos 184 municípios cearenses se encaixavam nessa categoria, quais sejam: Acaraú, Amontada, Aquiraz, Caucaia, Eusébio, Fortaleza, Horizonte, Iguatu, Itaitinga, Maracanaú, Maranguape, Meruoca, Pacatuba, Paramoti, São Gonçalo do Amarante, Sobral e Tauá. Assim, é possível perceber a presença nesse grupo de vários municípios pertencentes à Região Metropolitana de Fortaleza e de outros municípios com economias relativamente mais expressivas ou que se situam em áreas de serra e, consequentemente, apresentam melhores condições ambientais.

Além disso, é importante considerar que, conforme discutido anteriormente, os demais municípios só poderão melhorar as suas participações nos recursos se atenderem aos critérios estabelecidos, o que pode não ser fácil no curto prazo, pois pode demandar certo tempo e recursos que os municípios podem não dispor. $O$ mecanismo pode oferecer uma mobilidade aos municípios na obtenção de recursos, embora isto seja mais provável de acontecer em um prazo mais longo, ao contrário do ocorrido no caso dos demais índices considerados na metodologia de cálculo da cota parte do ICMS, de acordo com os resultados obtidos por Nogueira (2010).

Portanto, isso demonstra certa inconsistência do mecanismo do ICMS Ecológico em relação ao mecanismo mais geral do qual ele faz parte. E, assim, a pergunta que deve ser respondida nesse contexto é a seguinte: o que os municípios menos desenvolvidos e com menos 
recursos financeiros podem fazer para melhorar as suas condições socioambientais e, assim, atender aos critérios estabelecidos pelo ICMS Ecológico no Ceará?

\section{Considerações finais}

Conforme foi indicado anteriormente, o mecanismo de incentivo do ICMS Ecológico implementado recentemente no Ceará visava alcançar dois objetivos principais: elevar a competição dos municípios cearenses por recursos adicionais e, adicionalmente, promover uma redistribuição dos recursos decorrentes da arrecadação do ICMS que são transferidos aos municípios, de forma a beneficiar aqueles que possuem economias menos expressivas.

Com a análise de consistência do referido mecanismo, verificouse que, referente ao primeiro objetivo, é possível argumentar que o ICMS Ecológico teoricamente e de maneira geral o satisfaz sim, já que, para aumentar a participação nos recursos repassados aos municípios, os critérios propostos devem ser alcançados. Entretanto, as limitações citadas anteriormente valem como, por exemplo, no que se refere à dimensão do incentivo concedido e o estímulo à participação por parte dos municípios. No caso, cada município que mais rapidamente implementar as mudanças necessárias para satisfazer os referidos critérios poderá usufruir, pelo menos temporariamente, de um maior volume de recursos, já que à medida em que todos vão satisfazendo os critérios, as participações nos recursos vão tendendo a se tornar mais igualitárias. Aos municípios, cabe saber se os benefícios esperados são grandes o suficiente em comparação aos custos associados ao cumprimento dos cinco critérios propostos.

Já a análise do segundo objetivo revelou uma inconsistência ainda mais grave. No caso, ao invés de beneficiar aqueles que mais necessitam de recursos adicionais, como foi feito no caso dos demais mecanismos definidos a partir do IQE e do IQS, os critérios estabelecidos para o ICMS Ecológico são mais facilmente alcançados pelos municípios com economias mais expressivas, pois eles têm mais recursos para tanto. 
Assim, cria-se uma situação em que os municípios mais pobres precisam fazer grandes investimentos e esforços organizacionais e institucionais para poder aumentar as suas fatias dos recursos e, também, melhorar as condições socioambientais para a sua população. Então, o que fazer?

Uma estratégia que pode ser concebida com base na análise do marco lógico proposto é a realização de parcerias com os governos do Estado e Federal e, também, com organismos internacionais. Isso representaria uma redução na pressão por recursos, principalmente financeiros, que o município teria para implementar os requisitos previstos pelo ICMS Ecológico. Ademais, que alternativas haveria para que os impactos pretendidos sejam alcançados?

Visto que problemas ambientais são mais rapidamente e melhor resolvidos com o envolvimento da população, essas chances podem ser aumentadas caso haja um reforço na conscientização das pessoas para melhorar as condições ambientais da região, seja na implantação da coleta seletiva ou da sistemática, dentre os outros critérios. Intensificando a presença da população em estudos, pesquisas e debates sobre o ambiente em que vivem, procurando atingir a comunidade em geral, a fim de que todos possam ter acesso a estes conhecimentos.

Além da conscientização das pessoas com o intuito de melhorar as condições ambientais da região, a área do município poderia ser um dos parâmetros utilizados para a alocação dos recursos na gestão ambiental na tentativa de melhorar a distribuição para os municípios de pequeno porte, assim como descreve Schult (2010, p. 11):

[...] observa-se a dificuldade na municipalização da gestão ambiental, e também a urbana, em municípios de pequeno porte. As agendas prioritárias do século XX, como educação e saúde, institucionalizaram o repasse de recursos federais e estaduais, com base em cortes populacionais. Porém, para a agenda ambiental, que aponta como relevante no século $\mathrm{XXI}$, a área do município deveria ser um parâmetro para a alocação de recursos na gestão ambiental e territorial. Grande número de municípios brasileiros tem pequena população, mas um enorme estoque de recursos naturais sob sua jurisdição [...]. 
Em termos práticos, é possível utilizar um exemplo real, que foi objeto de estudo de mestrado de Schneider (2001), após realizar um trabalho de desenvolvimento sustentável na cidade de Teutônia no interior do Estado do Rio Grande do Sul. No caso, para que a cidade viesse a assumir uma posição proativa em relação à questão ambiental, algumas sugestões foram feitas, as quais podem ser bem utilizadas por outros municípios em situação parecida. A cidade situa-se em uma região rica em recursos naturais, que está predominantemente estruturada em pequenas propriedades rurais.

Segundo Schneider (2001), as sugestões para o melhoramento das condições socioambientais da região foram as seguintes:

- Primeiramente, realizar um diagnóstico ambiental completo do município, a fim de conduzir os trabalhos de acordo com as necessidades mais imediatas e de fornecer informações para o planejamento municipal de mais longo prazo;

- É necessário também que as empresas obtenham o licenciamento ambiental e que haja a fiscalização de suas atividades;

- Definir um conjunto de indicadores para avaliar a sustentabilidade do município e passar a monitorá-lo periodicamente;

- Buscar alternativas eficientes para a questão energética, buscando usar as fontes alternativas de energia;

- Desenvolver um trabalho mais intensivo nas escolas, fortalecendo a educação ambiental formal;

- Orientar a população para o aproveitamento do lixo orgânico, acrescentando-o na coleta seletiva em geral; e

- Intensificar as parcerias com empresas em geral para maior envolvimento dos grupos sociais nas diversas atividades desenvolvidas e maior comprometimento da comunidade.

Outro trabalho parecido foi um relatório de pesquisa elaborado por Pedrosa et al., em 2007, que mostrou as modificações ocorridas em cada cidade do interior do Estado de Pernambuco. Dentre elas, mostrou- 
se a importância da Agenda 21 Local, que é o plano estratégico de cada município para facilitar o desenvolvimento sustentável de uma região, sendo o seu principal objetivo o de formular e implementar as políticas públicas por meio da metodologia participativa.

Este trabalho mostra também as etapas de construção da Agenda 21, que podem ser de grande interesse aos municípios que ainda precisam de um planejamento estratégico para tal prática. São elas:

- Formação de um grupo de parcerias locais;

- Sensibilização da comunidade;

- Criação de um Fórum de Agenda 21;

- Levantamento de prioridade e diagnóstico participativo;

- Elaboração do Plano de Desenvolvimento Sustentável Local; e

- Implementação, monitoramento e revisão do plano.

Essas são algumas práticas já implementadas e com resultados satisfatórios que poderão ser usados como exemplo para que alguns municípios menos desenvolvidos e com menores condições possam utilizar para melhorar as suas circunstâncias socioambientais e, assim, atender aos critérios estabelecidos pelo ICMS Ecológico no Ceará.

Cabe aqui enfatizar que uma maior efetividade do ICMS Ecológico impõe, como essencial, o comprometimento de longo prazo dos gestores públicos com as políticas públicas de gestão ambiental e seus instrumentos, bem como a consolidação de programas institucionais para a conservação da biodiversidade, o que envolve investimentos, humanos e financeiros, e uma maior fiscalização por parte do poder público. Esses fatores, aliados à vontade e determinação política, participação e cobrança da sociedade, produzirão resultados positivos de grande alcance socioambiental.

Por fim, sugere-se que novos estudos sejam efetuados sobre a temática do ICMS Ecológico, utilizando-se uma abordagem mais desagregada, baseada em estudos de caso de alguns municípios específicos, em que as questões discutidas ao longo do trabalho, bem como os desafios e sugestões destacados nesta seção sejam 
considerados ainda com maior profundidade. Assim, será possível identificar histórias de sucesso e os fatores que foram fundamentais para tanto, que servirão como referência para os municípios que buscam mais recursos e a melhoria das condições socioambientais de suas populações.

\section{Referências}

ALMEIDA, L. T. Política ambiental: uma análise econômica. São Paulo: Fundação Editora da Unesp, 1998.

BARBIERI, J. C. Gestão ambiental empresarial: conceitos, modelos e instrumentos. 3. ed. São Paulo: Saraiva, 2011.

BISQUERRA, R.; SARRIERA, J. C.; MARTINEZ, F. Introdução à estatística: enfoque informático com o pacote estatístico SPSS. Porto Alegre: Artmed, 2004.

CAJAZEIRA, J. E. R.; BARBIERI, J. C. A nova versão da norma ISO 14.001: as influências presentes no primeiro ciclo revisional e as mudanças efetuadas. REAd, Porto Alegre, ed. 48, v. 11, n. 6, nov./dez. 2005.

CAMPBELL, D. E. Incentives: motivation and the economics of information. 2. ed. Cambridge: Cambridge University Press, 2006.

COSTA, L. O.; PAIVA, W. L. Memória de cálculo dos coeficientes de distribuição do ICMS municipal 2010. Fortaleza: Ipece, 2009. (Nota Técnica n. 39).

ELZEN, B.; Wieczorek, A. Transitions towards sustainability through system innovation. Technological Forecasting \& Social Change, New York, v. 72, 2005, p. 651-661.

GOULDER, L. H. Environmental policy making in a second-best setting. Journal of Applied Economics, Buenos Aires, v. 1, n. 2, p. 279328, nov. 1998. 
GUJARATI, D. N. Econometria básica. Rio de Janeiro: Elsevier, 2006. HAHN, R. W. Economic prescriptions for environmental problems: how the patient followed the doctor's orders. Journal of Economics Perspectives, Pittsburgh, v. 3, n. 2, p. 95-114, 1989.

HEMPEL, W. B. A importância do ICMS ecológico para a sustentabilidade ambiental no Ceará. Revista Eletrônica do Prodema, Fortaleza, v. 2, n. 1, p. 97-113, jun. 2008.

HOLANDA, M. C. (Org.) A prática de uma gestão pública por resultados. Fortaleza: IPECE, 2006. 203 p.

HOLANDA, M. C.; ROSA, A. L. T. Gestão pública por resultados na perspectiva do estado do Ceará. Fortaleza: Ipece, 2004. (Nota Técnica n. 11).

HOLANDA, M. C. et al. Proposta de mudança no rateio da cota parte do ICMS entre os municípios cearenses. Fortaleza: IPECE, 2007. (Texto para discussão n. 51).

INSTITUTO DE PESQUISA E ESTRATÉGIA ECONÔMICA DO CEARÁ. Índice de Desenvolvimento Municipal (IDM): Ceará - 2008. Fortaleza, 2010.

KREPS, D. M. Microeconomics for managers. New York: W.W. Norton, 2003.

LAFFONT, J. J.; MARTIMORT, D. The theory of incentives: the principal-agent model. Princeton: Princeton University Press, 2001.

MEDEIROS, A. C.; ROSA, A. L. T. ; NOGUEIRA, C. A. G. Gestão pública por resultados: uma análise comparativa entre os modelos do Ceará e do Canadá. In: ENCONTRO ECONOMIA DO CEARÁ EM DEBATE, 4., 2008, Fortaleza. Anais... Fortaleza: IPECE, 2008. CDROM.

NOGUEIRA, C. A. G. Efeitos distributivos das políticas públicas: o caso da nova metodologia de cálculo da cota parte do ICMS do Ceará. Revista FSA, Teresina, n. 9, p. 55-69, 2012. 
OECD. Economic instruments for environmental protection. Paris, 1992.

PEDROSA, I. V. et al. Os municípios e o meio ambiente em Pernambuco: relatório de pesquisa - 2006-2007. Recife: Universidade de Pernambuco, 2007.

PERMAN, R. et al. Natural resource and environmental Economics. London: Longman, 1996.

PIGOU, A. C. The economics of welfare. London: Macmillan, 1932.

PORTNEY, P. R. EPA and the evolution of federal regulation. In: RUSSO, M. V. (Org.). Environmental management: readings and cases. 2nd ed. Thousand Oaks: Sage, 2008. p. 79-92.

SALANIÉ, B. The economics of contracts: a primer. Cambridge: MIT Press, 1998.

SCHNEIDER, E. Gestão ambiental municipal: estudo de caso na administração municipal de Teutônia. 2001. 96 f. Dissertação (Mestrado em Administração) - Escola de Administração, Universidade Federal do Rio Grande do Sul, Porto Alegre, 2001.

SCHULT, S. I. M.; CUSTÓDIO, E. D .S. A evolução da gestão das áreas protegidas em meio urbano em pequenos e médios municípios. Disponível em: <http://www.anppas.org.br/encontro5/cd/artigos/GT9434-978-20100906145323.pdf>. Acesso em: 12 jan. 2011.

TIETENBERG, T. H. Economic instruments for environmental regulation. Oxford Review of Economic Policy, v. 6, n. 1, p. 17-33, 1990.

WOOLDRIDGE, J. M. Econometric analysis of cross section and panel data. Cambridge: MIT Press, 2002.

. Introdução à econometria: uma abordagem moderna. São

Paulo: Pioneira Thomson Learning, 2006.

Artigo recebido em: 31/10/2012

Aprovado em: 07/05/2013 